\title{
Improved Injection Behavior with the Addition of Granulated $\beta$-Tricalcium Phosphate in Brushite Bone Cement
}

\author{
Hyun-Ho Jo and Kyung-Sik $\mathrm{Oh}^{\dagger}$ \\ School of Advanced Materials Engineering, The Center of Biomedical Materials and Biotechnology, \\ Andong National University, Andong 36729, Korea
}

(Received September 5, 2018; Revised November 2, 2018; Accepted November 3, 2018)

\begin{abstract}
To improve the injection behavior of brushite cement, dense $\beta-\mathrm{Ca}_{3}\left(\mathrm{PO}_{4}\right)_{2}(\beta-\mathrm{TCP})$ granules were added to the starting material. The spherical $\beta$-TCP granules prepared by spray-drying and subsequent sintering at $1000 \sim 1200^{\circ} \mathrm{C}$ accounted for fractions of from 0.5 to 0.7 of the total $\beta$-TCP. The injection behavior was evaluated by measuring the injected mass divided by the loaded mass of paste in the syringe pump. The injected amount was increased with the increase in the fraction and sintering temperature of $\beta$-TCP granules, except at $1200^{\circ} \mathrm{C}$. The increase in the fraction of $\beta$-TCP and its sintering temperature resulted in a decrease in the plastic limit, which is the volume of water required to liquefy the compact. The rest water could be utilized in the cement with the reduced plastic limit for improved injectability. The amounts of rest water assigned for powdery phase were estimated, and correlated with the injectability of paste.
\end{abstract}

Key words : Bone cement, $\beta$-TCP Granule, Injection, Plastic limit, Granular fraction

\section{Introduction}

$I^{\mathrm{n}}$ surgery of skeletal bone tissue, the bone cement is widely used. Especially during kyphoplasty surgery, bone cement is injected into a fractured area of the involved vertebrae after inflating a balloon in the vertebrae. The inflation of the balloon returns the fractured pieces to a normal position and also compacts the soft inner bone to create a cavity inside the vertebrae. ${ }^{1)}$ As the cement paste is injected through a narrow needle in the cavity and hardens to stabilize the bone, the bone cement paste needs to be sufficiently injectable for the kyphoplastic application.

The definition of injectability is in dispute. . $^{2}$ In some studies, the injectability has been related to the easiness of the injection. ${ }^{3,4)}$ Therefore, the magnitude of the pressing force required to deliver a paste was the main concern. It is noted that filter pressing, the separation of powder and liquid, often occurs during the injection of the paste. $\left.{ }^{5}\right)$ As the powder/liquid ratio strongly affects end product ${ }^{6)}$ or strength ${ }^{7,8)}$ of paste, the filter pressed paste can result in a critical nonuniformity in the injected product. Thus, other studies highlighted the uniform quality of the injected paste and the ability of the paste to remain homogeneous has been emphasized as an indicator of injectability. ${ }^{9,10)}$

In this work, the injectability of cement was quantitatively evaluated by measuring the injected mass divided by the loaded mass in the syringe. ${ }^{11)}$ The injectability is closely

\footnotetext{
'Corresponding author: Kyung-Sik Oh

E-mail : ksoh@andong.ac.kr

Tel : +82-54-820-5783 Fax : +82-54-820-6211
}

related to the fluidity of the paste, which is dependent on the powder/liquid ratio. With added liquid, the injectability of the paste generally increases. In this work, increase in the practical amount of liquid was aimed by using granulated dense $\beta$-tricalcium phosphate $\left(\mathrm{Ca}_{3}\left(\mathrm{PO}_{4}\right)_{2}: \beta\right.$-TCP $){ }^{12)}$ indicating less amount of liquid on the solid surface.

The amount of liquid required to liquefy the powder compact is known as the plastic limit. Thus, the plastic limit refers to the minimum volume of mixing liquid needed to confer a liquid behaviour to the mixture ${ }^{13}$ and provides information about which paste is deformable for the injection. In this work, the plastic limit was determined for the compact of a granule/powder mixture by varying the fraction and sintering temperature of the granules. As the volume of water corresponding to the plastic limit is consumed for liquefaction, the amount of rest water was evaluated and compared with the injected ratio of the paste. The comparisons were made by varying the fraction and sintering temperature of the granules. It was shown that the amount of rest water and the injected ratio closely correlated with each other. To verify the uniformity of the paste, a phase analysis was carried out on the end products.

\section{Experimental Procedure}

The $\beta$-TCP granules (Sigma-Aldrich, Germany, 96\%, average particle size of $1.9 \mu \mathrm{m}$ ) were prepared by spray-drying ${ }^{12)}$ and subsequent sintering at $1000 \sim 1200^{\circ} \mathrm{C}$ for $2 \mathrm{~h}$. The morphologies of the granules were observed using scanning electron microscopy (SEM, Tescan VEGA II LMU). The cross-section of the $\beta$-TCP granules was exposed by lapping 
the granules fixed in the resin. After polishing with $1 \mu \mathrm{m}$ diamond paste, the inner structure of the granules was observed by SEM.

The paste was prepared by kneading $1 \mathrm{~g}$ of the powder mixture with 0.7 or $0.8 \mathrm{ml}$ of deionized (DI) water as the setting agent. The amount of setting agent was determined to secure sufficient fluidity and extended setting time for the injection. The cement powder consisted of $0.6 \mathrm{~g}$ of $\beta$-TCP and $0.4 \mathrm{~g}$ of $\mathrm{Ca}\left(\mathrm{H}_{2} \mathrm{PO}_{4}\right)_{2} \cdot \mathrm{H}_{2} \mathrm{O}$ (monocalcium phosphate monohydrate: MCPM, Sigma-Aldrich, Japan, 95\%). $\beta$-TCP was a mixture of sintered granules and as received powder with mixing ratios from 5:5 to 7:3. Injection was carried out using a syringe pump (Nexus 3000, CHEMYX, Korea) at a rate of $10 \mathrm{ml} / \mathrm{min}$ under $400 \mathrm{~Pa}$. As the setting time was longer than 3 minutes, the paste could be loaded in the syringe after kneading for $1 \mathrm{~min}$ in the dish. The amount of time required to complete the injection from the syringe was 12 sec. The injected amount was measured using a balance configured as shown in Fig. 1. By dividing the injected weight with the loaded weight in the syringe, the injected ratios were expressed as percentages.

For evaluation of the plastic limit $\left(V_{p l}\right)$, a $1 \mathrm{~g}$ mixture of the $\beta$-TCP powder and sintered granules was compacted by uniaxial pressing into discs with a diameter of $1 \mathrm{~cm}$. The mixing ratios between the sintered granule and the powder ranged from 5:5 to 7:3. The $\beta$-TCP compact was placed on a waterproof dish, and DI water was added using a micropi-

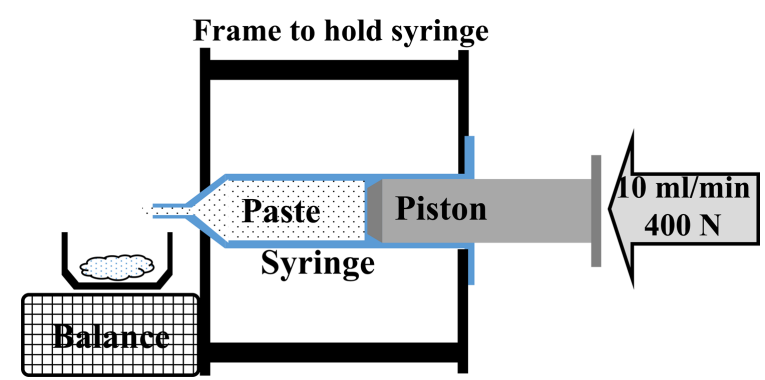

Fig. 1. Schematic illustration of the apparatus to evaluate the injection behavior of paste. pette until the beginning of the flow. The total volume of DI water supplied to the compact until the beginning of flow was regarded as the $V_{p l}$. After complete setting of the injected paste, the end product was analyzed using X-ray diffraction (XRD, D/MAX-2000, Rigaku, TX, US) and SEM.

\section{Results and Discussion}

The $\beta$-TCP granules used in the experiment had a rounded shape with a diameter (mode) of $125 \mu \mathrm{m}$. Fig. 2 shows the granules sintered at (a) $1000^{\circ} \mathrm{C}$, (b) $1100^{\circ} \mathrm{C}$, and (c) $1200^{\circ} \mathrm{C}$. At $1200^{\circ} \mathrm{C}$, the diameter decreased to $115 \mu \mathrm{m}$, as shown in Fig. 2(c). Sintering resulted in the densification of granules along with the coarsening of grains. The granules were $\beta$-TCP (JCPDS index of 9-169) according to the X-ray diffraction analysis regardless of the sintering temperatures. As a result of sintering at $1200^{\circ} \mathrm{C}$, the $\beta$-TCP granules had a porosity of $21 \%$ according to the image analysis

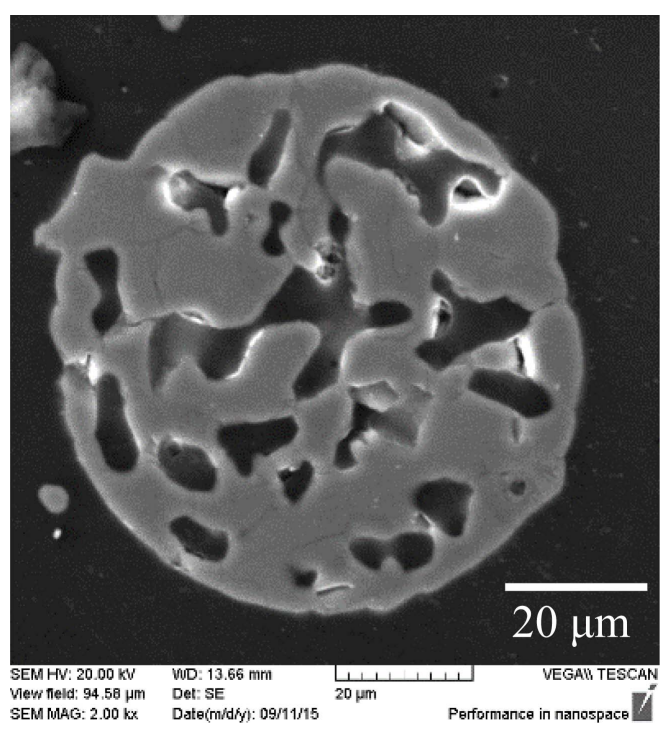

Fig. 3. Cross-section of $\beta$-TCP granule prepared via spraydrying and subsequent sintering at $1200^{\circ} \mathrm{C}$ for $2 \mathrm{~h}$.

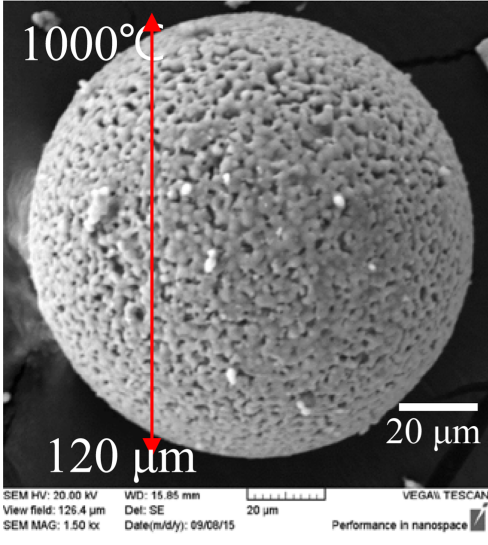

(a)

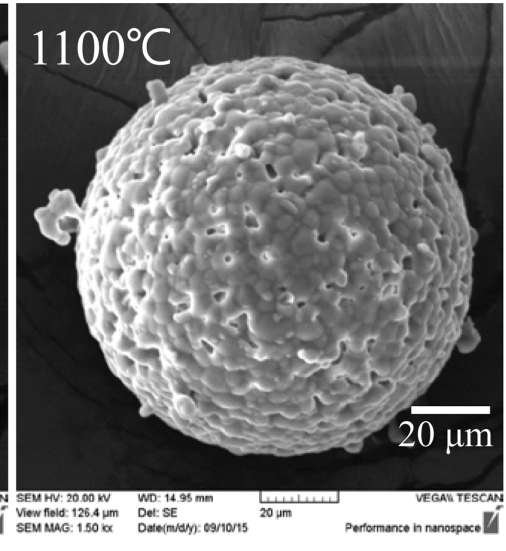

(b)

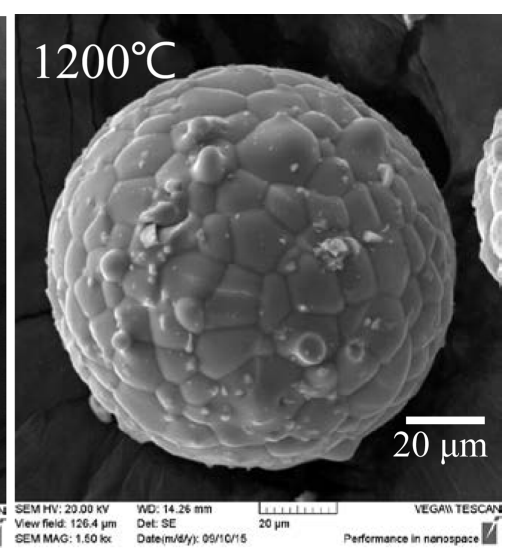

(c)

Fig. 2. $\beta$-TCP granules prepared via spray-drying and subsequent sintering at (a) $1000^{\circ} \mathrm{C}$, (b) $1100^{\circ} \mathrm{C}$, and (c) $1200^{\circ} \mathrm{C}$ for $2 \mathrm{~h}$. 
in the cross-section shown in Fig. 3. The paste prepared with $\beta$-TCP granule/powder, MCPM, and setting agent exhibited setting times from 180 to $750 \mathrm{~s}$ according to the estimation with a Vicat needle. The kneading and loading of the paste in the syringe required $90 \mathrm{sec}$, allowing injection of the paste using the syringe pump before the hardening of the paste.

Figure 4 shows the injected ratio (\%) with the fraction of granular $\beta$-TCP $\left(x_{G}\right)$ for various $\left(1000 \sim 1200^{\circ} \mathrm{C}\right)$ sintering temperatures. For the $\beta$-TCP granule sintered at $1000^{\circ} \mathrm{C}$, the injected ratio increased from $83 \%$ to $88 \%$ with an increase in $x_{G}$ from 0.5 to 0.7 . The increases in the injected ratio with the same increase in $x_{G}$ were enhanced as $11 \%$ and $10 \%$ with the granules sintered at 1050 and $1100^{\circ} \mathrm{C}$, respectively. Thus, both the absolute injected ratio and the increase in injected ratio were greater with the granules sintered at 1050 and $1100^{\circ} \mathrm{C}$ than those at $1000^{\circ} \mathrm{C}$. With the granules sintered at $1150^{\circ} \mathrm{C}$, the injected ratios ranged at elevated values of from $97 \%$ to $98 \%$, irrespective of the $x_{G}$. On the contrary, although the granules sintered at $1200^{\circ} \mathrm{C}$

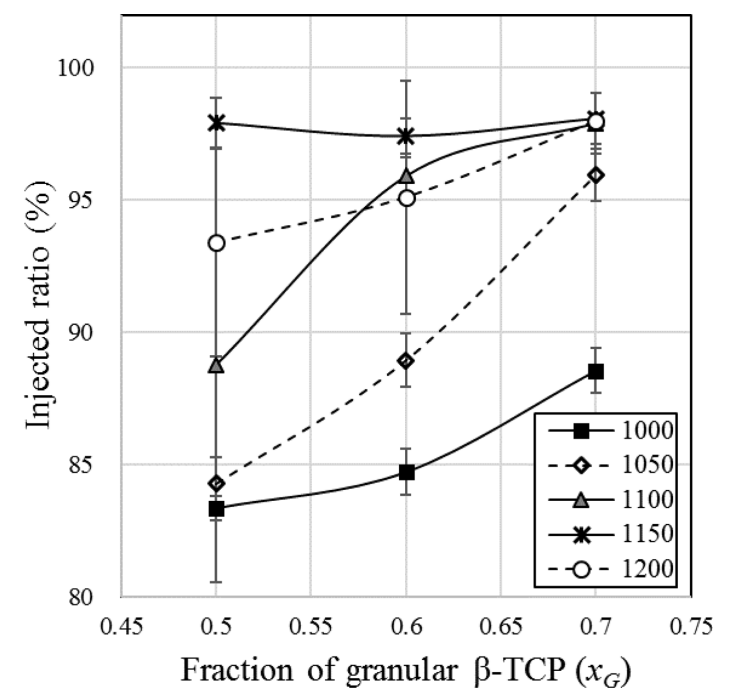

Fig. 4. Injected ratio (\%) of paste with the fraction of granular $\beta$-TCP in the paste. The granules were sintered at $1000^{\circ} \mathrm{C}$ to $1200^{\circ} \mathrm{C}$ for $2 \mathrm{~h}$. exhibited an increase in injected ratio from $93 \%$ to $98 \%$, the increase (5\%) was alleviated and the absolute injected ratios were less than those at $1150^{\circ} \mathrm{C}$.

Figure 4 shows that the addition of the $\beta$-TCP granules generally increases the injected ratio. Except for the result at $1200^{\circ} \mathrm{C}$, the increase in sintering temperature also increased the injected ratio. As the surface area of the granules is reduced compared to the powdery counterpart, less liquid is required to cover the surfaces of the granules. Thus, it is conjectured that the $V_{p l}$ of the granules is smaller than that of the powder. ${ }^{13)}$ The $V_{p l}$ can be experimentally determined by measuring the cumulative amount of supplied liquid at which the powder compact begins to flow under its own weight. Thus, the $V_{p l}$ provides direct information about which paste can be injected.

Figure 5 shows the process of measuring $V_{p l}$ for the $\beta$-TCP powder compact. Fig. 5 shows the powder compact after absorption of (a) $0.02 \mathrm{ml}$, (b) $0.52 \mathrm{ml}$, and (c) $0.54 \mathrm{ml}$ of water. From the liquefied compact observed in Fig. 5(c), $V_{p l}$ is $0.54 \mathrm{ml}$. Therefore, the $V_{p l} \mathrm{~s}$ were determined for the granules with the heat treatment temperature, as shown in

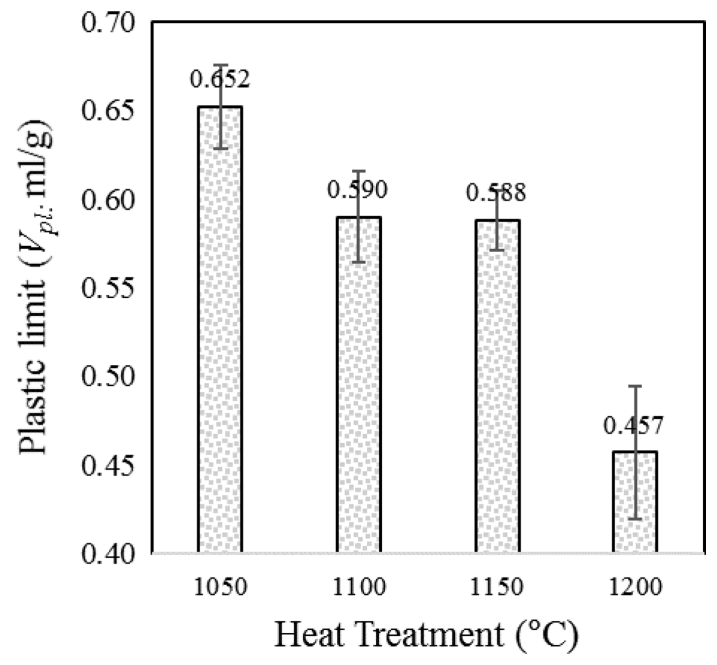

Fig. 6. Plastic limit of granular $\beta$-TCP compact with the heat treatment temperature of $\beta$-TCP granules.

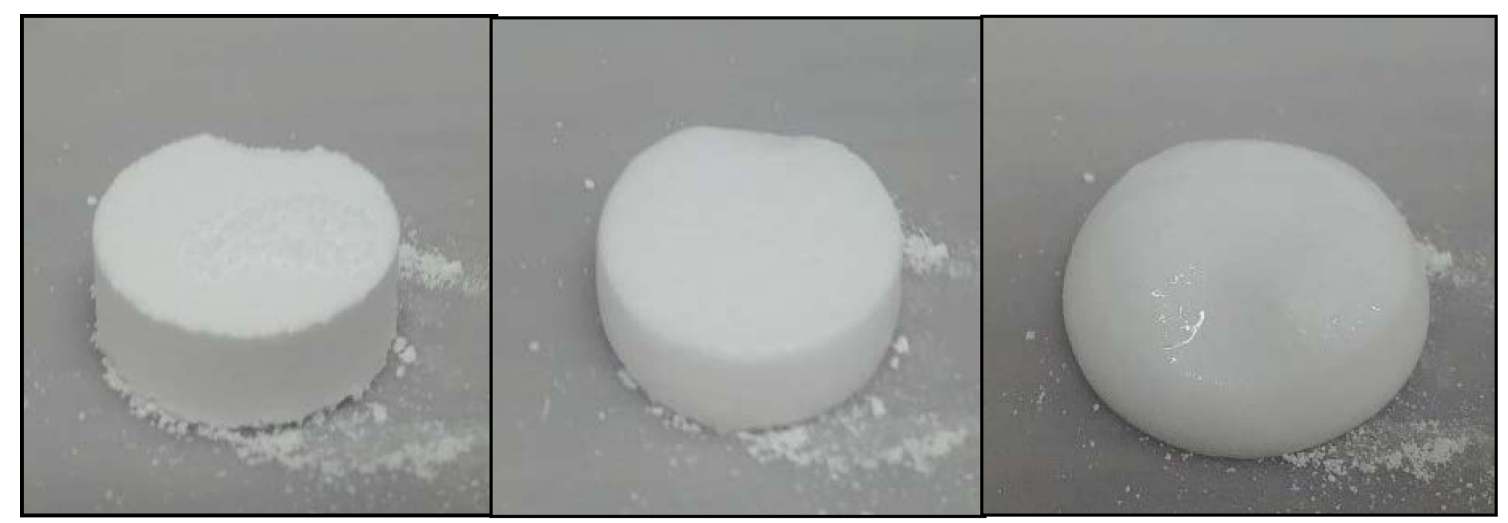

(a) (b) (c)

Fig. 5. $\beta$-TCP compact after absorption of (a) $0.02 \mathrm{ml}$, (b) $0.52 \mathrm{ml}$ and (c) $0.54 \mathrm{ml}$ of water. 


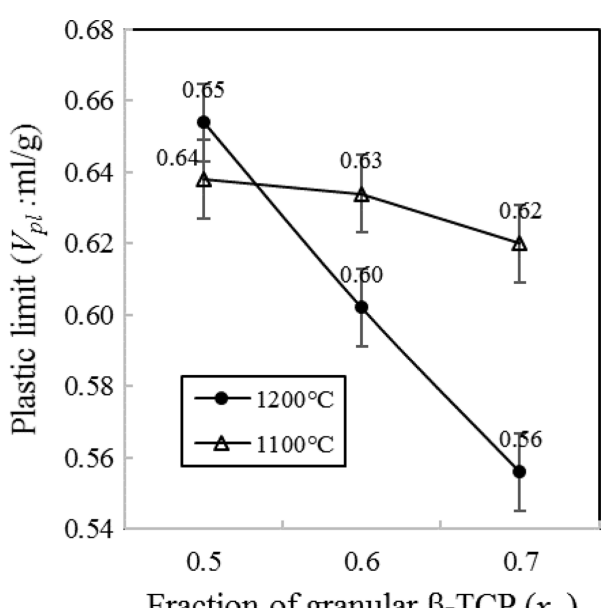

Fraction of granular $\beta$-TCP $\left(x_{G}\right)$

Fig. 7. Plastic limits of compacts prepared with mixture of $\beta$-TCP powder and $\beta$-TCP granule. The $\beta$-TCP granules were sintered at either $1100^{\circ} \mathrm{C}$ or $1200^{\circ} \mathrm{C}$ for $2 \mathrm{~h}$.

Fig. 6. With the increase in sintering temperature, the $V_{p l}$ values actually decreased. In particular, the $V_{p l}$ at $1200^{\circ} \mathrm{C}$ considerably decreased to $0.457 \mathrm{ml} / \mathrm{g}$. It should be noted that the pores were closed in the $\beta$-TCP granule with the sintering at $1200^{\circ} \mathrm{C}$. Thus, the granules sintered at $1200^{\circ} \mathrm{C}$ exhibited considerably reduced $V_{p l}$.

The $V_{p l}$ s were also estimated for the mixture of granule and powder as shown in Fig. 7. For the granules sintered at $1100^{\circ} \mathrm{C}$, the $V_{p l}$ gradually decreased from 0.64 to $0.62 \mathrm{ml} / \mathrm{g}$ with an increase in $x_{G}$ from 0.5 to 0.7. Due to the reduced $V_{p l}$ of granules, the decrease in the $V_{p l}$ is observed in the granule and powder mixture. In the case of granules sintered at $1200^{\circ} \mathrm{C}$, the $V_{p l}$ decreased rather steeply from 0.65 to 0.56 $\mathrm{ml} / \mathrm{g}$ at the same $x_{G}$. As the density of the $\beta$-TCP granule sintered at $1200^{\circ} \mathrm{C}$ was elevated, the $V_{p l}$ decreased, as shown in Fig. 6. The use of dense granules also resulted in reducing the $V_{p l}$ of the mixture, as shown in Fig. 7 .

From the results in Figs. 4 and 7, the injected ratio in Fig. 4 was inversely related to $V_{p l}$ in Fig. 7 at the same $x_{G}$. The $V_{p l}$ in Fig. 7 is the amount of water absorbed until liquefaction; therefore, the rest liquid is distributed to the powdery $\beta$-TCP. With additional liquid available for the powdery $\beta$-TCP, the fluidity of powdery $\beta$-TCP increases and the injection behavior is improved. Table 1 shows the calculation of the volume of water available for the unit amount of powdery $\beta$-TCP. First, the amount of water absorbed by the granules was calculated by multiplying the $x_{G}$ and $V_{p l}$ at the given $x_{G}$ shown in Fig. 7. Apart from the amount of water absorbed by the granules $\left(0.6 x_{G} V_{p l}\right)$ in the amount provided for setting $(0.8 \mathrm{ml})$, the rest water $(0.8 \mathrm{ml}$ $\left.-0.6 x_{G} V_{p l}(\mathrm{~T}) m l\right)$ was considered as the water available for powdery $\beta$-TCP. $V_{p l}(\mathrm{~T})$ represents the $V_{p l}$ of the compact prepared with granules sintered at temperature $T$. By dividing the water available for powdery $\beta$-TCP with the weight $\left[0.6\left(1-x_{G}\right)\right]$ of powdery $\beta$-TCP, the amount of water per unit amount of powder was calculated.

Table 1 shows that the water available for the unit amount of powdery $\beta$-TCP increases with the increase in $x_{G}$ at both 1100 and $1200^{\circ} \mathrm{C}$. Fig. 8 shows a schematic illustration of the mixture of granular and powdery $\beta$-TCP. The injection through the syringe requires deformation of the paste, which causes the positions of the granules and powder to change. As the granules are much larger than powder particles, the deformation of all of the paste is achieved by the modification of the powdery phase. As the fluidity of the powdery phase strongly depends on the amount of liquid phase mixed with the powder, it is important to ensure that the information on the amount of water is available for powdery $\beta$-TCP. According to Table 1, the amount of water per unit amount of powdery $\beta$-TCP increases from 2.03 to $3.00 \mathrm{ml} / \mathrm{g}$ with $x_{G}$ at $1100^{\circ} \mathrm{C}$. As more water is available for powdery $\beta$-TCP with the increase in $x_{G}$, the increase in the injected ratio shown in Fig. 4 is rea-

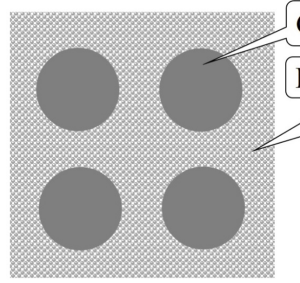

(a) Loaded in syringe

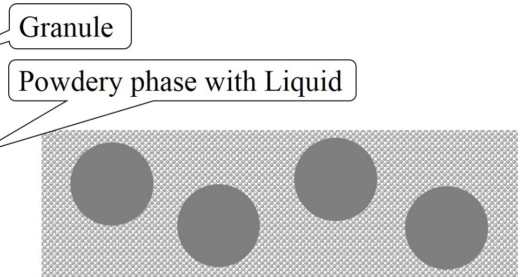

(b) During the injection
Fig. 8. Schematic illustration of the paste (a) loaded in the syringe and (b) during the injection.

Table 1. Water Available for Unit Amount of Powdery $\beta$-TCP with the Fraction of Granular $\beta$-TCP Heat-Treated at 1100 and $1200^{\circ} \mathrm{C}$

\begin{tabular}{|c|c|c|c|c|}
\hline & $x_{G}:$ fraction of granule & 0.5 & 0.6 & 0.7 \\
\hline \multirow{4}{*}{$\begin{array}{c}\beta \text {-TCP } \\
\text { heated at } \\
1100^{\circ} \mathrm{C}\end{array}$} & $V_{p l}$ (1100): Plastic limit at $1100^{\circ} \mathrm{C}(\mathrm{ml} / \mathrm{g})$ & 0.64 & 0.63 & 0.62 \\
\hline & Water absorbed by granular $\beta$-TCP in $0.6 \mathrm{~g}$ of $\beta$-TCP $\left\{=0.6 x_{G} V_{p l}(1100) \mathrm{ml}\right\}$ & 0.19 & 0.23 & 0.26 \\
\hline & Water available for powdery $\beta$-TCP in $0.6 \mathrm{~g}$ of $\beta$-TCP $\left\{=0.8 \mathrm{ml}-0.6 x_{G} V_{p l}(1100) \mathrm{ml}\right\}$ & 0.61 & 0.57 & 0.54 \\
\hline & Water per unit amount of powdery $\beta$-TCP $\left\{=\left[0.8 \mathrm{ml}-0.6 x_{G} V_{p l}(1100)\right] /\left[0.6\left(1-x_{G}\right)\right] \mathrm{ml} / \mathrm{g}\right\}$ & 2.03 & 2.38 & 3.00 \\
\hline \multirow{4}{*}{$\begin{array}{c}\beta \text {-TCP } \\
\text { heated at } \\
1200^{\circ} \mathrm{C}\end{array}$} & $V_{p l}$ (1200): Plastic limit at $1200^{\circ} \mathrm{C}(\mathrm{ml} / \mathrm{g})$ & 0.65 & 0.60 & 0.56 \\
\hline & Water absorbed by granular $\beta$-TCP in $0.6 \mathrm{~g}$ of $\beta$-TCP $\left\{=0.6 x_{G} V_{p l}(1200) \mathrm{ml}\right\}$ & 0.20 & 0.22 & 0.23 \\
\hline & Water available for powdery $\beta$-TCP in $0.6 \mathrm{~g}$ of $\beta$-TCP $\left\{=0.8 \mathrm{ml}-0.6 x_{G} V_{p l}(1200) \mathrm{ml}\right\}$ & 0.60 & 0.58 & 0.57 \\
\hline & Water per unit amount of powdery $\beta$-TCP $\left\{=\left[0.8 \mathrm{ml}-0.6 x_{G} V_{p l}(1200)\right] /\left[0.6\left(1-x_{G}\right)\right] \mathrm{ml} / \mathrm{g}\right\}$ & 2.01 & 2.43 & 3.15 \\
\hline
\end{tabular}




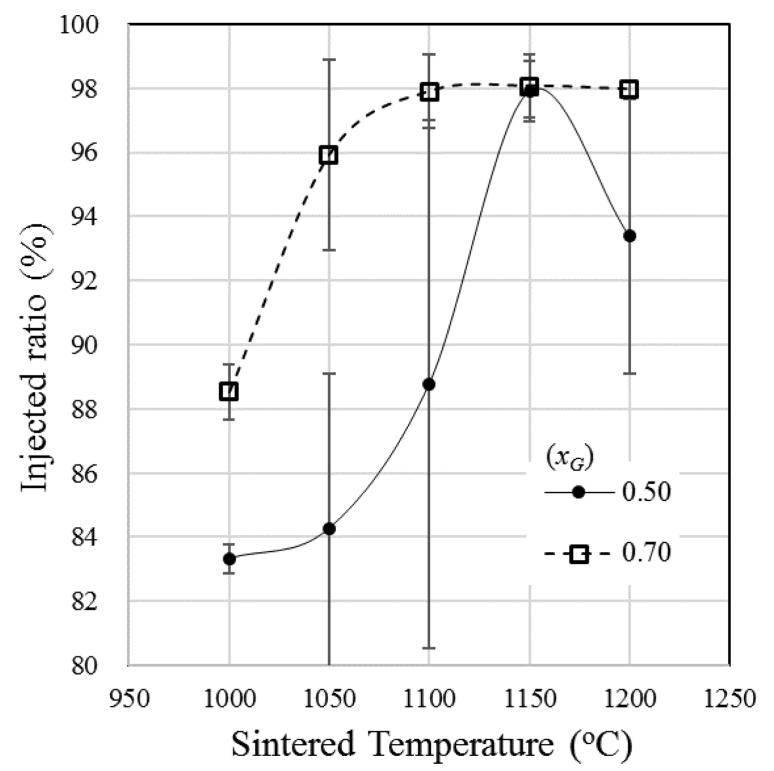

Fig. 9. Injected ratio (\%) of paste with the sintering temperature of granular $\beta$-TCP. The fraction of granules was either 0.5 or 0.7 of total $\beta$-TCP.

sonable. The granules sintered at $1200^{\circ} \mathrm{C}$ also exhibited an increase in the amount of water per unit amount of powdery $\beta$-TCP from 2.01 to $3.15 \mathrm{ml} / \mathrm{g}$ at the same $x_{G}$. As shown in Fig. 4, the injected ratio also increased with $x_{G}$ at $1200^{\circ} \mathrm{C}$.

The injected amounts were expressed with the sintering temperature of granules as shown in Fig. 9. At $x_{G}=0.7$, the injected ratio increased and was saturated at $98 \%$ with the increase in sintering temperature. As the increase in sintering temperature reduced $V_{p l}$, the rest water could be used to improve the injection behavior. At $x_{G}=0.5$, the injected ratio reached a peak at $1150^{\circ} \mathrm{C}$. The absolute values of the injected ratio were less than those at $x_{G}=0.7$. At $x_{G}=0.5$, as fewer granules were added, the amount of reduced $V_{p l}$ was less than that at the $x_{G}=0.7$. Thus, due to the greater $V_{p l}$ at

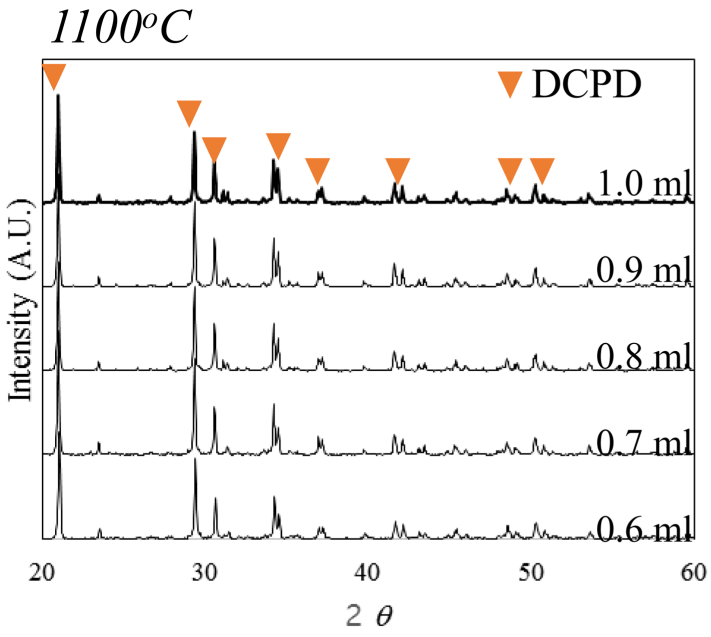

(a)

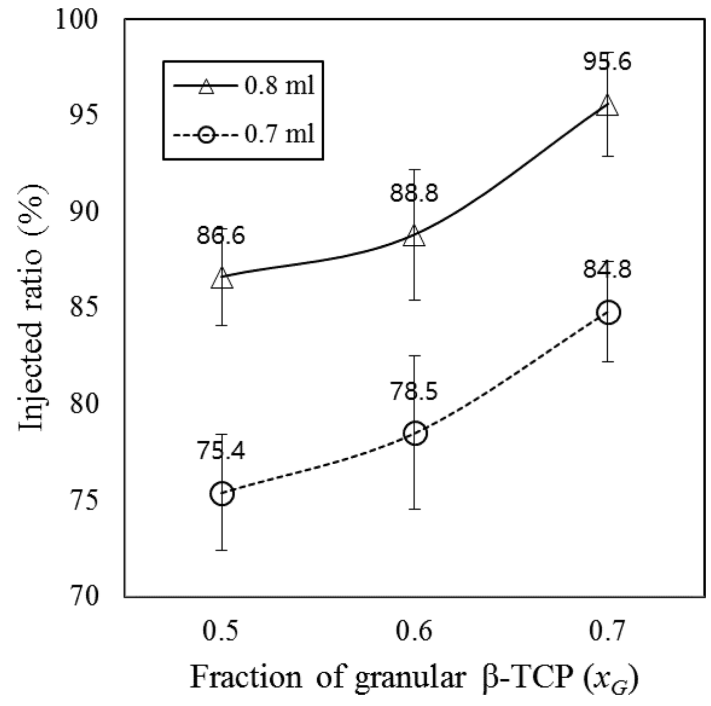

Fig. 10. Injected ratio (\%) of paste with the fraction of granular $\beta$-TCP in the paste. The granular $\beta$-TCP was sintered at $1150^{\circ} \mathrm{C}$ and mixed with either 0.7 or 0.8 $\mathrm{ml}$ of setting agent.

$x_{G}=0.5$, a less amount of water is assigned for powdery $\beta$ TCP than that at $x_{G}=0.7$. Therefore, the injected ratios at $x_{G}=0.5$ were reduced, as shown in Fig. 9 .

Thus, the amounts of remaining water left at $V_{p l}$ in Table 1 closely correlate with the injected ratio. The hypothesis can also be tested by the reduction of setting agent for the same cement powder. Fig. 10 shows the injected ratio with the reduced amount $(0.7 \mathrm{ml})$ of setting agent with the same powder. The $\beta$-TCP granules were heated at $1150^{\circ} \mathrm{C}$. Fig. 10 shows that reducing the amount of setting agent reduced the injected amount for the entire $x_{G}$. Since the plastic limits of the two cement mixture are the same, the reduction of setting agent to $0.7 \mathrm{ml}$ reduced the amount of rest water for powdery $\beta$-TCP. Therefore, the reduction of the amount of setting agent renders the paste less injectable.

\section{$1200^{\circ} \mathrm{C}$}

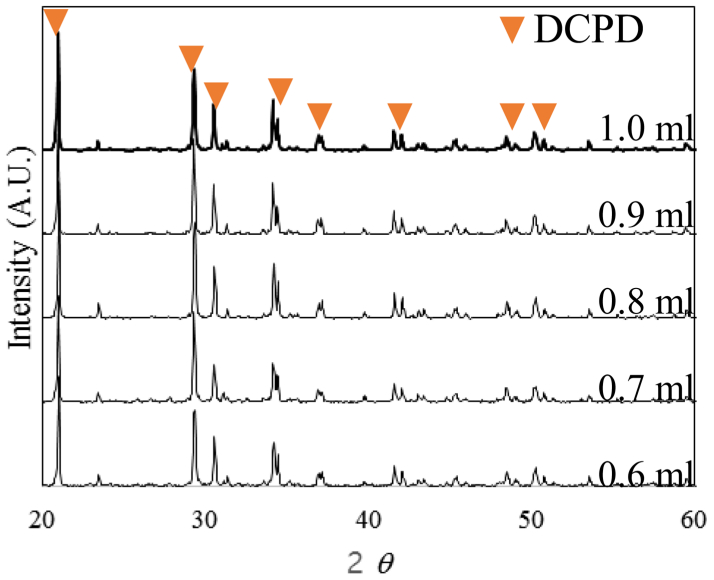

(b)

Fig. 11. X-ray diffracton patterns of paste prepared with $\beta$-TCP granules and various amount setting agents. The $\beta$-TCP granules were sintered at either (a) $1100^{\circ} \mathrm{C}$ or (b) $1200^{\circ} \mathrm{C}$. 


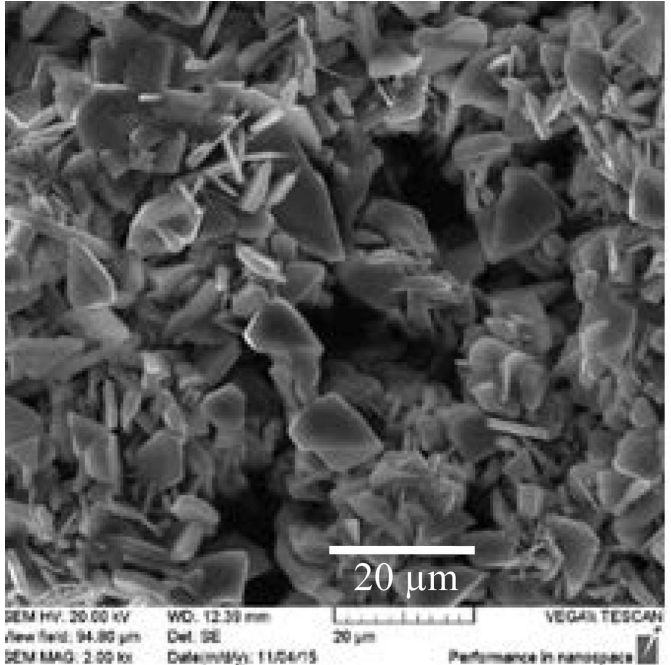

(a)

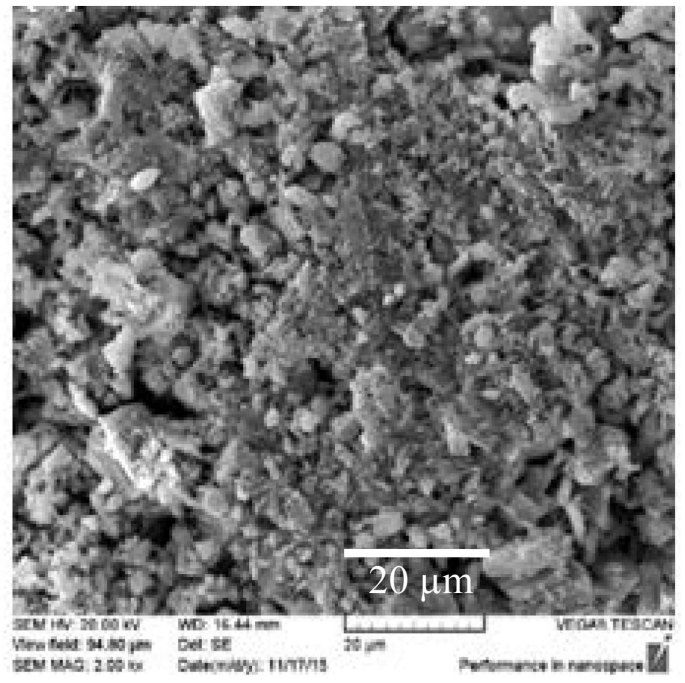

(b)

Fig. 12. Microstructure of injected paste prepared with $\beta$-TCP granules sintered at either (a) $1100^{\circ} \mathrm{C}$ or (b) $1200^{\circ} \mathrm{C} \mathrm{using} 0.8 \mathrm{ml}$ of setting agent.

As explained in the introduction, agreement on the definition of the injectability has generally not been reached. Either the ease of injection or the uniformity of the injected paste is emphasized regarding the definition of injectability. In terms of the uniformity, various parameters need to be verified. In this work, the phase after setting was first observed using X-ray diffraction. Fig. 11 shows the diffraction patterns of paste prepared with $\beta$-TCP heated at 1100 and $1200^{\circ} \mathrm{C}$. Regardless of the amount $(0.6 \sim 1.0 \mathrm{ml})$ of setting agent tested per $1 \mathrm{~g}$ of cement, the end products only contained dicalicum phosphate dehydrate (DCPD: CaH$\mathrm{PO}_{4} \cdot 2 \mathrm{H}_{2} \mathrm{O}$ ). Despite the increase in setting agent for the sake of injection, dicalcium phosphate (DCP: $\mathrm{CaHPO}_{4}$ ) was not found. It has been reported that while the formation of DCP can take place using an excessive amount of setting agent ${ }^{6,14)}$ and this resulted in deteriorated properties of cement. ${ }^{14)}$ Fig. 12 shows the microstructures of injected pastes prepared with $\beta$-TCP granules heated at 1100 and $1200^{\circ} \mathrm{C}$. The pastes were composed of particles with developed habits, which is typical for DCPD crystals.

The results shown in Figs. 4 and 9 indicate that the appropriate $x_{G}$ is close to 0.7 . As the $V_{p l}$ of the mixture decreased with the increase in granular fraction, an improved injection behavior is expected. However, it should be noted that $x_{G}$ greater than 0.7 can result in collisions among the granules. In this case, the deformation ability of the paste can be aggravated. In practice, under the condition in which the collision of granules is not anticipated, the $V_{p l}$ was shown to be a useful parameter to explain the injection behavior.

\section{Conclusions}

The injection behavior of brushite bone cement prepared with granular $\beta$-TCP was investigated. The spherical $\beta$-TCP granules, sintered at $1000 \sim 1200^{\circ} \mathrm{C}$, accounted for granular fractions of from 0.5 to 0.7 of the total $\beta$-TCP. The injected ratio increased with the increase in granular fraction $\left(x_{G}\right)$ and the sintering temperature of granules. The change in the injected ratio was explained in terms of the plastic limits $\left(V_{p l}\right)$. Other than the amount of water needed for liquefaction $\left(V_{p l}\right)$, the rest water was used to increase the fluidity at the same volume of setting agent. The amount of rest water per unit amount of powder phase closely correlated with the injected ratio of the paste.

\section{Acknowledgments}

This work was supported by a grant from 2017 Research Funds of Andong National University.

\section{REFERENCES}

1. S. M. Belkoff, J. M. Mathis, and L. E. Jasper, "Ex Vivo Biomechanical Comparison of Hydroxyapatite and Polymethylmethacrylate Cements for Use with Vertebroplasty," AJNR Am. J. Neuroradiol., 23 [10] 1647-51 (2002).

2. J. Zhang, W. Liu, V. Schnitzler, F. Tancret, and J. M. Bouler, "Calcium Phosphate Cements for Bone Substitution: Chemistry, Handling and Mechanical Properties," Acta Biomater., 10 [3] 1035-49 (2014).

3. M. P. Ginebra, A. Rilliard, E. Fernandez, C. Elvira, J. San Roman, and J. A. Planell, "Mechanical and Rheological Improvement of a Calcium Phosphate Cement by the Addition of a Polymeric Drug," J. Biomed. Mater. Res., 57 [1] 113-18 (2001).

4. U. Gbureck, K. Spatz, R. Thull, and J. E. Barralet, "Rheological Enhancement of Mechanically Activated $\alpha$-Tricalcium Phosphate Cements," J. Biomed. Mater. Res. B, 73B [1] 1-6 (2005). 
5. M. Habib, G. Baroud, F. Gitzhofer, and M. Bohner, "Mechanisms Underlying the Limited Injectability of Hydraulic Calcium Phosphate Paste. Part II: Particle Separation Study," Acta Biomater., 6 [1] 250-56 (2010).

6. M. Bohner and U. Gbureck, "Thermal Reactions of Brushite Cements," J. Biomed. Mat. Res. B, 84B [2] 375-85 (2008).

7. F. Tancret, J. M. Bouler, J. Chamousset, and L. M. Minois, "Modelling the Mechanical Properties of Microporous and Macroporous Biphasic Calcium Phosphate Bioceramics," J. Eur. Ceram. Soc., 26 [16] 3647-56 (2006).

8. F. Pecqueux, F. Tancret, N. Payraudeau, and J. M. Bouler, "Influence of Microporosity and Macroporosity on the Mechanical Properties of Biphasic Calcium Phosphate Bioceramics: Modelling and Experiment," J. Eur. Ceram. Soc., 30 [4] 819-29 (2010).

9. M. Bohner and G. Baroud, "Injectability of Calcium Phosphate Pastes," Biomaterials, 26 [13] 1553-63 (2005).

10. M. Boner, "Design of Ceramic-based Cements and Putties for Bone Graft Substitution," Eur. Cells. Mater., 20 1-12 (2010).

11. I. Khairoun, M. G. Boltong, F. C. M. Driessens, and J. A. Planell, "Some Factors Controlling the Injectability of Calcium Phosphate Bone Cements," J. Mater. Sci.: Mater. Med., 9 [8] 425-28 (1998).

12. I. C. Lee, T. J. Chung, and K. S. Oh, "Preparation of Brushite Bone Cement with a Drug Containing $\beta$-Tricalcium Phosphate," Key Eng. Mater., 720 143-46 (2017).

13. H. Andrianjatovo, F. Jose, and J. Lemaitre, "Effect of $\beta$ TCP Granularity on Setting Time and Strength of Calcium Phosphate Hydraulic Cements," J. Mater. Sci.: Mater. Med., 7 [1] 34-9 (1996).

14. S. A. Lee, T. J. Chung, and K. S. Oh, "Effect of Storage Conditions on the Setting Properties of Brushite Bone Cement Containing Granular $\beta$-Tricalcium Phosphate," $J$. Korean Ceram. Soc. 45 [10] 624-29 (2008). 